\title{
Analysis of Sri Lankan Power System Total Failures Initiated by Double Circuit Outages of Kothmale -Biyagama 220kV Transmission Line.
}

\author{
A.C.S. Wijayatilake
}

\begin{abstract}
Power system operational records [1] for the past fifteen year period were examined and it can be inferred that double circuit outage of $220 \mathrm{kV}$ transmission line between Kothmale and Biyagama (KB line) switching stations is the reason for many of the blackouts that have occurred in the past. It has been noted that many of the total failures that occurred in the past were initiated by multiple lightning strokes on the KB line.
\end{abstract}

Though total failures caused by the $\mathrm{KB}$ line outages became less during the last period of four years it is a timely requirement to focus more attention again on the total system failures caused by the KB line outages because the $150 \mathrm{MW}$ new hydro power station is scheduled to be commissioned in 2010 in Upper Kothmale and the power generated at this power station is planned to be dispatched to the main load centres using the same transmission line.

In this study, system behaviour at steady state as well as transient state was analysed at different contingencies of the $\mathrm{KB}$ line in order to find out the root cause for resulting total failures. System was analysed with PSS/E software.:Power system analysis tools such as Load flow, fault analysis, and stability studies were extensively utilized to understand and describe the events observed during system failures.

System investigations reveal that the probability of outage of both circuits of the $K B$ line due to simultaneously occurring faults in both circuits is extremely low. Simulation results suggest that the total failures are initiated by the disconnection of one circuit of the Kothmale-Biyagama line due to a fault and the disconnection of the remaining circuit within a small time period due to voltage instability experienced in the system. The system voltage instability following outage of one circuit of the $\mathrm{KB}$ line is justified by reviewing PV and PQ curves of some selected busses. By analysing the simulation results, recommendations are made to overcome future blackouts.

\section{Introduction}

Total system failures occurring in the national power grid result in enormous difficulties to the public life and a considerable loss to the national economy. It also brings two main types of challenges to power system operators. The main challenge is to restore the supply within a minimum period of time and the other is to conduct a post-mortem to find out answers for thousands of questions raised by politicians, academia, professionals and general public. Since a power system is a dynamic system it is impossible to eliminate total failures completely even though sophisticated equipment are used and professional engineers engage in system operations in a well developed control centre equipped with modern IT and communication facilities. There is a probability for unseen faults taking place in hardware or software systems.
On the other hand human mistakes happening in system operational and maintenance activities cannot be completely eliminated. Additionally, power system is subject to unavoidable natural environmental disasters such as lightning, flood or storms. Hence, total system failures cannot be eradicated.

Since blackouts are caused by cascading failures of transmission network facilities within a considerably small time period it is very difficult to identify the exact root cause easily. A detailed investigation should be conducted analysing the automatically recorded data at various power facilities, log sheets maintained by operating

Eng. A C S Wijayatilake, BSc Eng., C.Eng., MIE(Sri Lanka) 
staff and observations made by the maintenance staff subsequent to the failure. Sinulation of a power system model validated with the actual system is widely used to understand the system behaviour during total failures to determine the exact reason for cascading tripping and to find out remedial measures. Contribution of professionals working at different sectors of power system management such as operation, planning, design, maintenance etc is essential to correctly interpret the simulation results in order to find out the exact root cause. Otherwise the responsibility will be transferred on uncontrolled environmental factors, most probably lightning strokes on transmission lines.

When power system operational records [1] for the past fifteen year period are examined it can be seen that the Sri Lankan power system experiences at least one total failure per year. The available information further reveals that the reason for many of the blackouts occurring in the past were due to the failure of both circuits of $220 \mathrm{kV}$ double circuit transmission line between Kothmale and Biyagama switching stations. It is a $70.5 \mathrm{~km}$ long $220 \mathrm{kV}$ double circuit transmission line constructed with twin Zebra conductors on steel lattice towers mainly to bring the power generated in the Mahaweli complex to the main load centres around Colombo. It has been noted that many of the total failures which occurred in the past were initiated by simultaneous outage of both circuits of the Kothmale-Biyagama transmission line as a consequence of multiple lightning strokes on both circuits.

In recent years total failures caused by the $K B$ line outages are less due to the fact that the percentage contribution of Mahaweli generation is becoming less compared with the rapid increase in the total demand. However, it is a worthwhile and a timely requirement to focus more attention again on the total system failures caused by the $\mathrm{KB}$ line outages because the $150 \mathrm{MW}$ new hydro power station is scheduled to be commissioned in 2010 at Upper Kothmale and the power generated in this power station is planned to be dispatched to main load centres using the same $\mathrm{KB}$ transmission line.

The objective of this study was to investigate the system behaviour at steady state as well as in transient state at one or two circuit contingencies of the KB line in order to identify the exact reason for the resulting total failures. System was analysed with a detailed network model developed using PSS/E software. Power system analysis tools such as Load flow, fault analysis, and stability studies were extensively utilized to describe the events observed during system failures initiated by double circuit outages of the $\mathrm{KB}$ line and to identify the exact reasons for the system collapse. Through network simulations, recommendations are made to minimize the threat for future blackouts.

\section{Power Transmission Network of Sri Lanka}

Sri Lankan power transmission system consists of $331 \mathrm{~km}$ long $220 \mathrm{kV}$ network and a $1684 \mathrm{~km}$ long $132 \mathrm{kV}$ network during the year 2008 . Both $220 \mathrm{kV}$ and $132 \mathrm{kV}$ systems are interlinked at Rantembe, Kotugoda, Biyagama, Anuradhapura, Pannipitiya and Kelanitissa switching stations. Mahaweli and Kelanitissa power generating complexes are connected to the $220 \mathrm{kV}$ network and rest of the generation stations are connected to the $132 \mathrm{kV}$ system.

The daily peak demand occurs between $7 \mathrm{pm}$ and $9 \mathrm{pm}$ and the maximum night peak demand recorded in 2008 was $1922 \mathrm{MW}$. Day time maximum demand and daily minimum demand were $73 \%$ and $40 \%$ of the daily peak demand respectively. The daily minimum demand occurs between $1 \mathrm{am}$ and 3am. During the rainy season (wet season) hydro power is extensively utilized to meet the demand. The three main hydro power complexes are Mahweli, Laxapana and Samanelawewa. Both Mahaweli and Laxapana are situated in the hill country and the power generated in these power stations are dispatched to main load centres through long transmission lines. During the dry season thermal power dominates. Due to the lack of sufficient machines to meet the demand it is a common practice to operate gas turbines and diesel power plants at base load. Six number of $220 / 132 \mathrm{kV}$ switching stations and 44 nos of $132 / 33 \mathrm{kV}$ grid substations are connected to the transmission network to dispatch power. The transmission network consists of over head transmission lines with ACSR conductors mounted on steel towers including a $13 \mathrm{~km}$ length of $132 \mathrm{kV}$ underground cable network within the Colombo City supply. System operations are conducted by the System Dispatching Centre established in Colombo. Part of the transmission facilities are connected to the SCADA System and at present it is limited only to monitoring purposes. 
Kothmale and Biyagama 220kV Line (KB Line)

$220 \mathrm{kV}, 70.5 \mathrm{~km}$ long, double circuit line from Kothmale power station to Biyagama switching station was energized in 1984 to dispatch hydro power generated at the Mahaweli complex power stations namely Kothmale, Victoria, Rantembe and Randenigala. The maximum power generated at Mahaweli complex is nearly $660 \mathrm{MW}$. Due to the environmental factors maximum generation is possible only during raining (wet) season. ACSR type duplex Zebra (400sqmm) is used as a conductor of the KB line. This overhead line consists of two circuits mounted on steel lattice towers. The circuit is designed for a maximum $700 \mathrm{C}$ conductor temperature. The thermal rating at night time and day time is $1450 \mathrm{~A}$ and $1960 \mathrm{~A}$ respectively. Two series of distance protection schemes (Permissive under reach transfer tripping) consisting of two types of distance relays from two different manufactures were used to protect the line. Single phase auto reclosing facility and breaker failure protection is incorporated. Distance relays, CT windings and circuit breaker trip coils are duplicated to improve reliability of operation. Two power line carrier channels are used to transmit the trip signal between relays located at both ends. To provide maximum lightning protection two earth wires are mounted with zero shielding angles [2].

\section{Study Approach}

Power system was modelled with PSS/E software. Modelling included detailed generator models, exciter and governor models of all generators, distance protection of the $\mathrm{KB}$ line and for a few of the other selected lines, over current protection of Randenigala and Anuradapura $220 / 132 \mathrm{kV}$ transformers and under frequency load shedding scheme.

To study the steady state operation, load flow studies were conducted for three different demand periods noted in the daily load curve namely night peak, day peak and minimum load situations. The study was carried out for two different generation scenarios, wet season and dry season. In the wet season hydro power is used at maximum and during the dry season thermal power dominates. Steady state operation was examined at normal operation with two circuits of the $K B$ line in service as well as single and double circuit contingencies of the $\mathrm{KB}$ line.
Transientstability was investigated by simulating a three phase line fault at the most critical point of the considered line and observing relative rotor angle variations of generators during the operational period of the line protection scheme during and after the faulty line was switched off. Operation of primary and back up distance protection schemes to clear the three phase line fault were studied at different operating conditions. Feasible delay in distance protection operation due to the failure of the power line carrier was specially studied. Stability study covers the operation of the auto-reclosing facility incorporated in the distance protection scheme for the clearance of fault which is transient in nature.

The long term dynamic stability analysis was carried out in order to identify any persistent power oscillations on one circuit of the KB line immediately after the other circuit was isolated due to a fault or a maintenance requirement.

Finally, long term stability studies were carried out to investigate relay quantity swings of protection relays and to identify the cascading sequence of transmission line and generators in a blackout initiated due to the sudden outage of both circuits of the KB line.

Voltage stability studies were conducted by mapping $P, Q$ curves of some selected busbars at normal and outage operations of the KB line to verify voltage instability observed at long term simulations.

\section{Analysis of Power System at Steady State Operation}

The steady state operation was analysed by conducting load flow [3] studies by considering the normal operation as well as one and two circuit contingencies of the KB line. Since the system generation dispatch schedule is dependent on the climatic variations, this analysis was done for two different generation scenarios; wet season and dry season. During the wet season hydro power is utilized at maximum and in the dry season thermal power dominates. Thermal power stations are located closer to the main load centres but hydro stations are far away from the load centres, As a consequence the network loading is entirely different at the two generating scenarios. Load flow studies were carried out for three different demands situations namely night peak, day peak and minimum load operating conditions 
to accommodate demand variations noticed in the daily demand curve. The cost optimized merit order used in generation scheduling when meeting the demand was followed in this study. To meet the night peak load the available installed capacity was just sufficient and hence there were no noticeable generation schedule differences at night peak load conditions in both wet and dry seasons. Load flow results corresponding to the two generation scenarios and three demand conditions are presented in Table 1 and Table 2.

Analysis of Steady State Operations: Both Circuits of the KB Line in Service

As shown in Table 1 it can be observed that during the wet season system voltage profile is lower and system losses are higher than in the dry season. Since the power produced in hydro generators has to flow over long distances, the reactive power loss during the wet season is significantly higher than in the dry season irrespective of the load conditions. The higher reactive power flow results in higher active power losses as well as comparatively lower bus bar voltages especially at load centres in distant places. Thermal power plants are closer to industrial load centres and hence during the dry season the reactive power flow through the transmission network is less than in the wet season. As a consequence the voltage profile at load busses is higher and active and reactive power losses are comparatively less in the dry season.

The loading on Kothmale to Biyagama line is significantly higher during the wet season than in the dry season. The results show that the percentage loading of two circuits against the thermal rating of the line at night peak, day peak and off peak load conditions in wet season are $30 \%, 29 \%, 18 \%$. The corresponding loadings in dry season are $13 \%, 29 \%, 11 \%$ respectively.

Lower active power losses and a higher voltage profile is noticed in off peak load conditions. At off peak load condition the reactive power flow on the $\mathrm{KB}$ line is considerably low since the reactive power generated by transmission lines of the network is a significant portion of the reactive power demand of the system. Hence, reactive power flow is less and the resulting voltage profile is higher at off peak load conditions. The higher voltage profiles results in lower active power losses.
Results show that at all the generating scenarios and loading conditions the steady state system performance is satisfactory when the two circuits of the $\mathrm{KB}$ lines are in service. In the wet season, at day and night peak demand conditions, reactive power generation of all hydro generators reach higher values and flows to load centres through long transmission lines. Hence, at day and night peak load conditions voltages at certain busses are slightly lower than the allowable limit. At night peak, switched shunt capacitors available at grid substations provide maximum possible reactive power and tap changers of grid substation transformers of a few substations located at end points of the network adjust to maximum possible limits in order to increase distribution of bus bar voltage. For instance, tap changers of power transformers at grid substations in Iginiyagala, Ampara are operating at the maximum possible higher values. There are no over loaded equipments noticed in any of the operating conditions considered.

\section{Steady State Operations: One Circuit of the KB Line is in Service}

This case referred to the sudden disconnection of one circuit of the KB line. There was no other change on system operating conditions compared with the previously used base case load flow model. Load flow study was initiated with converged base case model and one circuit was disconnected to evaluate the system performance. Results corresponding to one circuit outage of Kothmale -Biyagama line are shown in Table 2 . In night peak load condition, Outage of one circuit increases the loading on the other circuit by 1.7 times. Especially in the wet season the reactive power flow along the $\mathrm{KB}$ line is significantly higher and as a result the voltage profile is considerably lower than in the case studied for normal operations. Apart from that, higher active and reactive power system losses can be noticed in the one circuit outage case. In wet and dry seasons at night peak and day peak load conditions the hydro generators supply the maximum possible reactive power at operating conditions corresponding to one circuit of the KB line which is in service.

Results shows that the voltage profile at day peak load demand in the wet season is considerably low due to higher reactive power losses caused by the excessive reactive power flow on the in service circuit of the $\mathrm{KB}$ line. 
However the system is in a critical operating condition at day and night peak demand conditions in the wet season and night peak demand condition in the dry season. The lower voltage profile indicates that there is a scarcity of reactive power in the network though all the reactive power sources in the system are contributing the maximum possible amounts. All equipments are operating without violating the thermal limits. Excessive low voltages can be noticed on Kotugoda $220 \mathrm{kV}$ bus in night peak load condition in the wet season.

Hence, it can be determined that the system is not robust enough to meet any more transmission or generation contingencies. Therefore system operating mode transits from normal operating mode to the emergency operating mode when one circuit of the $\mathrm{KB}$ line is out of service at night and day peak load demand conditions in both considered generation scenarios.

\section{Steady State Operations: Both Circuits of the KB Line are out of Service.}

This case referred to the sudden disconnection of both circuits of the $\mathrm{KB}$ line. There was no other change on system operating conditions compared with the previously used base case load flow model. Load flow study was initiated with converged base case model and both circuits were disconnected to evaluate the system performance. When both circuits of $\mathrm{KB}$ line are disconnected, the load flow calculation does not converge at any loading conditions in the wet season. Severe reactive power deficiency avoids converging bus bar voltages to the acceptable accuracy level. As a consequence generators try to operate on unfavourable operating zones defined in their capability curves to increase reactive power production. Tap changers of busbars automatically adjust and lock at the end of the maximum allowable limit without having any more voltage control capability. All reactive power sources produce the maximum possible reactive power. However, reactive power production is not sufficient to bring bus voltages to values high enough in order to have a converged load flow results. Gauss-Siedal and Newton-Raphson algorithms failed and even algorithms for approximate load flow results such as Decoupled Newton-Rapshon algorithm could not converge even for 150 iterations with minor adjustment on converging coefficients. The lack of a mathematical solution indicates the non existence of a realistic power system.
It further indicates that total system failure is unavoidable when both circuits of the $K B$ line are not in service at night peak and day peak load conditions in wet season and at peak load condition in the dry season.

Results confirm that load flow algorithms converge to a solution at day peak and off peak loading conditions in the dry season. However, voltage profile is extremely low and reactive power sources are operating at the maximum allowable end limits. Even though mathematical solution exits and load flow calculation converges the lower voltage profile of the network and unfavourable operating points of reactive power generating devices indicate that the network is operating in extreme operating mode. System cannot sustain even small network changes like transformer tap adjustments which can cause further increase in the reactive power requirement.

Hence, it can be reasonably concluded that double circuit outage of the $\mathrm{KB}$ line results in a total blackout at all demand conditions in the wet season and peak demand condition in the dry season.

\section{Identification of Possible Reasons for Double Circuit Outages of the KB Line}

It is necessary to identify the possible reasons for double circuit outages of the $\mathrm{KB}$ line in order to study resulting blackouts and look for mitigation measures. When all possibilities are concerned two circuit outages can take place at the following situations.

1. Faults occurring simultaneously on two circuits

Since two circuits are well maintained, the effect of way leaves can be neglected. Only lightning surge on to a tower top and resulting back flash over may disconnect two circuits simultaneously. But probability is very low.

2. Fault initiates on one circuit and spread the fault on to the other circuit

Similar to the previous case, lightning is the only possible cause for creating faults on two circuits within a small time difference. The main lightning stroke hits on one circuit and the return stroke hits on the other circuit may disconnect both circuits within a small period of time. On 
the other hand lightning stroke on one circuit may black flash over the other circuit.

3. One circuit is isolated due to a fault and the second circuit outage is due to instability of the network caused during or after the faulty circuit is isolated

Isolation of the fault on one circuit may cause system instability. The healthy circuit is disconnected by mal-operation of relays due to relay quantity swinging taking place at system unstable situations. System instability may be either one or a combination of transient, dynamic and voltage instability.

As discussed previously it can be concluded that the two circuit outages can be caused either by lightning or by system instability.

When tower dimensions, soil types, shielding angles and terrain are considered the probability for lightning to cause simultaneous outage of both circuits of the KB line is extremely low. Hence it is necessary to carry out a proper study to investigate the risk of system instabilities during or after the faulty circuit isolation.

Investigating System Stability During and After the Isolation of a Faulty Circuit of the KB Line

The objective was to study the possibility for the healthy circuit disconnection during or after the faulty circuit was cleared by system protection activation. There are three types of stability violation that can take place at different time frames.i.e. transientstability, dynamic stability or voltage stability[3]. To carry out stability studies, all generators in the network are modelled with $\mathrm{d}, \mathrm{q}$ transient model and the control circuits of exciters and governors are incorporated. Some of the generators do not have all the necessary parameters for detailed modelling. At similar instances, values were assumed by considering data of identical machines operating in other systems. The validity of exciter and governor models were evaluated through simulations of governor and exciter step response tests for each individual generators. Slight adjustments have been carried out for controllers dependent on the performance of individual units.

Over and under exciter limiters were imposed on exciter loops to prevent generators operating at unrealistic operating points producing higher or lower reactive power in extreme operating conditions.

Stability study results are sensitive to load composition. Since actual data is not available for the Sri Lankan system it was assumed that $100 \%$ of reactive power loads are of constant current type loads. Active power loads consists of $60 \%$ of constant currents loads and $40 \%$ of constant impedance loads. These assumed load characteristics brings about conservative results.

\section{Transient Stability Analysis}

The objective of conducting transient stability analysis was to investigate the possibility of loosing the synchronism of generators operating in the network while the faulty circuit of the $\mathrm{KB}$ line is being disconnected. A three phase fault is simulated at Kothmale $220 \mathrm{kV}$ bus bar end of the circuit no.1.of the KB line. Fault clearance procedure was investigated for three different possibilities.

Fault cleared by the operation of primary protection.

Results show that the system is stable up to $200 \mathrm{~ms}$ critical clearing time. The system is stable.

Fault cleared by the activation of primary protection with unsuccessful circuit auto reclosing

Fault was cleared at $100 \mathrm{~ms}$ after initiating the fault. After $0.4 \mathrm{~s}$ time period the circuit breaker recloses and energizes the faulty circuit again. Since the fault is still not cleared the circuit breaker opens and discomnects the circuit again. After $0.4 \mathrm{~s}$ time period the line recloses and since the fault is permanent in nature the line is disconnected permanently.

Results show that system is stable during the unsuccessful auto reclosing procedure. Though auto reclosing facility is limited for single phase faults clearing procedure, the simulation results are on optimistic side.

Fault cleared by the operation of secondary protection at Biyagama end due to the failure of communication channel 
Three phase fault is simulated at Kothmale end at time $=0 \mathrm{~s}$. The faulty circuit is disconnected at $100 \mathrm{~ms}$ by the activation of primary protection circuit breaker at Kothmale end. However the requesting signal is not sent to the relay at Biyagama end due to the failure of the communication channel. Then faulty line is connected at Biyagama end until the circuit is disconnected by the operation of back up protection at Biyagama $200 \mathrm{~ms}$ after the fault initiation.

Results indicate that the system is stable.

At all three instances the system was found to be stable. All generators are stable and no significant power swings were noticed at healthy circuit in cases 1 and 2 . In case 3 considerably small power swings were observed on the healthy circuit but died out within 1.2 seconds. The voltage drops on bus bars were within the allowable limits.

The results indicated that no transient instability was noticed during the isolation of a single circuit of the KB line due to a fault.

\section{Dynamic Stability Analysis}

Dynamic stability [3] studies were conducted aiming to investigate the possibility of experiencing persisting power swings following networkdisturbances. Longlasting powerswings with continuously increasing magnitude may develop on the in service circuit for a sufficiently long period after the isolation of one circuit either for maintenance work or clearance of the line fault. The same program used for studying transient stability was used to investigate the dynamic stability. Before starting simulations, $5 \%$ step changes were applied to the reference voltages of Automatic Voltage Regulators (AVR) of all generators. Variations of excitation and terminal voitages were investigated at open circuit conditions for tunning AVR loop controllers in order to eliminate power swings due to higher AVR gains.

When time $t=0$, a three phase fault was simulated on one circuit of the Kothmale-Biyagama line and the faulty circuit was switched off by activation of the line distance protection scheme. System simulation was continued to see any power oscillations on the healthy circuit. The stability simulation was carried out for a 20 s period and it was found that no persisting power swings were generated on the healthy circuit. It has been observed that the power swings created on the healthy circuit following the isolation of the faulty circuit damped out within $2 \mathrm{~s}$. Hence it can be concluded that there was no possibility of isolating the healthy circuit that resulted in a total blackout due to dynamic instability caused by a single circuit outage of the KB line.

\section{Long Term Stability Analysis}

Long term transient stability [3] studies were carried out to investigate the performance of relaysinstalled forsystem protection. Thedistance protection scheme of the $\mathrm{KB}$ line and KothmaleAnuradapura $220 \mathrm{kV}$ line were modelled with Mho relay characteristics: Mechanisms which may be incorporated in distance relays for blocking relay quantity swings were not modelled due to the lack of exact information. Distance protection system were roughly modelled on all other lines assuming Mho relay characteristics with three different protection zones of $40 \%, 60 \%$ and $120 \%$. Over current protection relays with IDMT characteristics were modelled for $220 / 132 \mathrm{kV}$ transformers at Anuradapura and Rantembe switching stations. In actual practice, $220 / 132 \mathrm{kV}$ transformer at Rantembe switching station is protected with Definite Time over current relays. Usage of IDMT relay characteristics for transformer over loading protection in this simulation model is more realistic since the maximum allowable overloading time of a power transformer is directly related to the overloading level. In the simulation model, IDMT relay settings were fixed to disconnect the transformer at $1.8 \mathrm{~s}$ if loading is between $125 \%$ and $150 \%$ of the rating and to disconnect immediately if percentage loading is above $150 \%$ of the rating. Under frequency load shedding scheme was modelled to study the effectiveness of the planned frequency sensitive automatic load disconnection during the occasions experiencing load and demand mismatches.

Stability studies was continued by simulating a three phase fault at Kothmale end on circuit no. 1 of the $K B$ line and allowed distance relays modelled at two ends of the both circuits to clear the fault automatically. Results show that the faulty circuit is disconnected by the activation of zone 1 relay on Kothmale end after $120 \mathrm{~ms}$. However, $90 \mathrm{~ms}$ after disconnecting the faulty circuit, the distance relay at Kothmale end to protect the healthy circuit responds to apparent 
fault impedance entering in to the zone 3 of Mho relay characteristics. Since the apparent impedance seen by the relay lasts sufficiently enough time within zone 3 characteristic and operate the timer corresponding to the $3^{\text {rd }}$ operating zone of the protection relay. The healthy circuit is isolated at time $t=1.33 \mathrm{~s}$. As pointed out in load flow analysis outage of both circuits of the KB line causes cascaded tripping of lines and generators leading to a total failure.

Based on the outcome of the long term stability analysis, detailed description about the operation of system protection relays and sequence of resulting cascaded line and generator trippings are presented in the following section.

Identification of the Chronological Order of Events Taking Place during the Total Failure Initiated by Double Circuit Outage of the KB Line

When a fault is simulated on Kothmale end of the circuit no. 1 at time $t=0$, the apparent impedance loci of Mho distance relay at Kothmale end of the same circuit enters immediately into zones 1,2 and 3 . Simultaneously the over current relay of Rantembe interbus transformer notices the high current flowing through it and the pickup timer starts. The faulty circuit of the $\mathrm{KB}$ line is disconnected after $120 \mathrm{~ms}$ by activating the zone 1 of the distance relay for circuit 1 of the $\mathrm{KB}$ line located at Kothmale end. The impedance vs. time locus of the Mho type distance protection relay mounted on Kothmale -Biyagama circuit no.1 is shown in Fig.1. During the period of faulty circuit isolation, the voltage of all buses of the network fall down to very low values less than $0.7 \mathrm{pu}$. The voltages measured on Ampara $132 \mathrm{kV}$, Biyagama $220 \mathrm{kV}$, Pannipitiya $220 \mathrm{kV}$ and Victoria $220 \mathrm{kV}$ buses are shown in Fig.2. As shown in Fig.2, immediately after the faulty circuit is disconnected the voltage starts improving due to the activation of reactive power reserves in generators and shunt capacitors. However, the rate of increase is very low. After disconnecting the faulty circuit, power flow on the in service circuit is increasing as shown in Fig.3. Oscillations of power, frequency and generator angles slowly settle down on a new steady state by time $t=230 \mathrm{~ms}$.

However, at time $t=230 \mathrm{~ms}$ the apparent impedance calculated by the distance relay protecting circuit no. 2 of the KB line on Kothmale bus becomes lower than the threshold value and impedance loci enters into the zone 3 of the Mho relay as shown in Fig..4. Hence, relay quantity swinging is noticed on the distance protection relay at Kothmale end protecting the in service circuit of the $\mathrm{KB}$ line.

Since one circuit of the $\mathrm{KB}$ line is already isolated the network pre-fault power flow pattern has changed. Power flow through remaining KB circuit no.2 and Rantembe, Anuradhapura interbus transformers increase. As indicated in Fig.5, the active and reactive power flow through the Rantembe interbus transformer increase continuously and transformer loading exceeds more than $150 \%$ of the rating at $460 \mathrm{~ms}$. As a consequence, Rantembe interbus transformer is switched off due to the activation of the over current relay. If the disconnection of the Rantembe transformer is further delayed (since it is protected with definite time over current relay with $1.6 \mathrm{~s}$ time setting irrespective of the degree of overloading) the simulation results are still valid. Because as shown in Fig. 7 , angles of generators at Kothmale, Victoria and Randenigala separate from the angles of the rest of the generators by $250 \mathrm{~ms}$ and increase continuously indicating the loss of synchronism. Violation of angular transient stability of Kothmale, Victoria, Randenigala and Rantemebe generators causes severe power fluctuations on the connected lines.

At time $=580 \mathrm{~ms}$, the apparent impedance calculated by the Mho relay protecting KothmaleAnuradapura line at Kothmale end becomes lower than the threshold value for activation of zone 3 relay. The apparent inpedance locus enters into the third zone and starts the zone 3 timer. The impedance locus is plotted on the relay characteristics as indicated in Fig.6.

Angles of Mahaweli complex generators are increasing continuously. On the otherhand Mahaweli machines are subjected to severe power fluctuations and increase the danger for pole slipping. The machine angles of selected generators are presented in Fig.7.

At time $=720 \mathrm{~ms}$ the apparent impedance loci entered on to the zone 3 of distance protection relay of Kothmale-Anuradhapuara line moves away from the operating region and the timer resets as shown in Fig..6.

At time $=730 \mathrm{~ms}$, angles of Rantembe generators reach to higher values as shown in Fig.7. 
Machines were isolated by activation of generator protection schemes to avoid generator pole slipping.

The apparent impedance entered into the operating region of 3 rd zone of the distance protection relay at Kothmale end remains in the zone sufficiently enough time to operate the distance protection scheme disconnecting the healthy circuit. As shown in Fig.4, at time $t=1.33 \mathrm{~s}$, the timer corresponding to the zone 3 of the distance protection relay of the healthy circuit of the $\mathrm{KB}$ line times out disconnecting the circuit. All remaining generation from Mahaweli complex is dispatched to Anuradhapuara grid since it is the only line connected to the Mahaweli generation complex. At $t=1.36 \mathrm{~s}$, two transformers at Anuradhapura grid are disconnected by activating over current relays. Over current relay characteristics of Anuradhapura transformer is shown in Fig.8.

Generator angle variations shown in Fig.7 indicate that the system is separated electrically into two sections. One island consists of Kothmale, Victoria and Randemigala power stations and the other consists of the remaining network. As shown in Fig.9, all connected generators in the Mahaweli complex become over speed due to the sudden load rejection caused by tripping of all connections with rest of the grid. The large angle deviations are noticed in the Mahaweli Complex generators compared with the angles of generators connected in the rest of the system. Frequency of the isolated Mahaeli island increases rapidly as shown in Fig.10. This abnormal high frequency is due to the disconnection of the electrical supply from the generating complex. Machines are disconnected as a precautionary measure due to the activation of out of step relays or over speed relays.

The remaining network experiences severe active and reactive power shortages as shown in Fig.11. The frequency of the rest of the system decreases rapidly and at $t=2.3 \mathrm{~s}$ the frequency reaches $48.8 \mathrm{~Hz}$ limit and under frequency load shedding relays activate and disconnect $72 \mathrm{MW}$ of the load. However, that action is not sufficient to cover the mismatch created between the load and the generation. The frequency variations of some busbars are shown in Fig.10.

Fig.12 shows time variation of electrical, mechanical and accelerating power of the total system. The accelerating power of the system becomes high at initial stage during the fault but slowly decreased when the machines increase production. Due to activation of load shedding slow increase in acceleration power can be noticed at later stages.

Rapidly decreasing voltage and frequency result in maximum utilization of switched shunt capacitor banks and generator spinning reserves. As a consequence, remaining generators increases active and reactive power output. Active and reactive power generation of Polpitiya generator is shown in Fig.13 As shown in the figure the reactive power generation is limited by the over excitation limiters of AVR loop to avoid field overheating due to high current flow associated with higher reactive power generation. Hence the reactive power supply cannot be increased to cover reactive power shortage seen in the system. The deficit in reactive power causes further lower voltage profile as shown in Fig.2. All generators allowable for free governor responses increase their active power supply up to the maximum allowable limit governed by the prime mover. The activation of generator spinning reserve and load shedding relays cannot completely cope with the demand-load mismatch created by isolating Mahweli generators. The mismatch in active and reactive power results in frequency and voltage to decrease continuously.

All remaining generators of the system disconnects one by one due to activation of the under frequency relay, operating of exciter protection system and failu re of auxiliary supply motors due to decreasing system voltage leading to a total system collapse.

\section{Reasons for Relaying Quantity Swings Observed in Zone 3 of Distance Protection Relays}

Long term stability results show that when one circuit of the $K B$ line is isolated due to a fault there is a possibility for quantities of the distance protection relay protecting the healthy circuit to start swinging. When one circuit is suddenly isolated the reactive and active power supply through the healthy circuit increases to higher values rapidly. At the same time the voltage at the line end start decreasing since the reactive power supply through remaining circuit is not adequate to keep the acceptable higher voltage profile on the Biyagama end as shown in load flow results. Hence, the higher current flow and lower bus voltage results in apparent impedance 
seen by the third zone of the distance protection relay to be lower than the threshold value. After the faulty circuit is isolated, the reactive power flow on the healthy circuit will increase but not settle back on the pre-faulty situation. The reactive power support to main load centres are very limited and the resulting low voltage profile further limits the effective reactive power supply of capacitor banks installed at a few grids. Voltage on the transmission system is continuously decreasing due to the activation of on load automatic transformer tap changers to fix decreasing distribution bus voltages. Hence the voltage profile is improving at a slow rate. Activation of exciter limiters limit generator VAr supply and make the situation worse. The time period taken by VAr sources to improve the system voltage profile is sufficient for zone three distance protection relay to operate its timer and disconnect the healthy circuit.

Long term stability results indicate that maloperation of the distance protection scheme is caused by the low voltage profile due to the reactive power deficit created following the outage of one circuit of the $\mathrm{KB}$ line. It further indicates that the system is operating closer to its voltage instability operating point. $\mathrm{PV}$ and $\mathrm{PQ}$ curve analysis are carried out in order to further verify the voltage instability situation seen at the long term stability analysis.

\section{Investigation on Voltage Instability Following One Circuit Outage of the KB Line}

Further investigation on voltage stability is carried out by plotting PV, QV curves of some selected busses corresponding to different outage situations of the $K B$ line.

QV curve for Biyagama $220 \mathrm{kV}$ bus is illustrated in Fig.12.The figure indicates that at normal operations bus bar voltage is at minimum acceptable level, $0.95 \mathrm{pu}$. To raise the voltage to $1 \mathrm{pu}, 370 \mathrm{MVAr}$ injection is required. When one circuit is disconnected Biyagama $220 \mathrm{kV}$ bus voltage drops to $0.9 \mathrm{pu}$ and the reactive power margin reduces from 400MVAr to 140MVAr. When both circuits are disconnected there is no realistic operating point and 400MVAr injection is required for Biyagama $220 \mathrm{kV}$ bus to operate at $0.95 \mathrm{pu}$ voltage. Table. 3 shows reactive power margin, voltage margin and required reactive power injection to keep the bus voltage at the minimum acceptable voltage level of few selected busses before and after one circuit outage. As shown in the table, reactive power margin at Pannipitiya $220 \mathrm{kV}$ bus drops to $67 \mathrm{MVAr}$ when one circuit of the $\mathrm{KB}$ line outage condition.

PV curves were developed by considering power transfer from Mahaweli complex to the rest of the system. PV curve for Biyagama $220 \mathrm{kV}$ busbar is shown in Fig.13. The figure shows that the maximum possible transfer of power is $450 \mathrm{MW}$ at normal operations and it reduces to $300 \mathrm{MW}$ when one circuit outage of the KB line occurred. Table 4 shows voltage and load corresponding to a system collapsing situation and the maximum possible power transfer of selected busses in normal operation as well as one circuit in outage conditions. When one circuit is out the power transfer through Biyagama, Kelanitissa and Sapugaskanda reduces to $300 \mathrm{MW}, 300 \mathrm{MW}$ and $250 \mathrm{MW}$ respectively. As indicated in the load flow, $342 \mathrm{MW}$ is transferred through one circuit of the KB line when the other is isolated and it is higher compared with power transfers given in Table 4.

According to PV and QV curves of Biyagama and Panipitiya $220 \mathrm{kV}$ busses it can be concluded that one circuit isolation of the $\mathrm{KB}$ line results in system voltage instability. Further to that the results justify the observations made at load flow studies and long term stability analysis.

\section{Conclusions of the Analysis}

1. There is a risk of the blackout following a double circuit outage of the $\mathrm{KB}$ line during dry season night peak load condition and in any demand condition in wet season.

2. The probability for disconnecting both circuits by simultaneously occurring line faults is extremely rare. The only possible instance is due to the back flashing over caused by a direct lightning stroke. However, such a probability is extremely low.

3. There is a possibility of disconnecting the healthy circuit immediately after the isolation of the faulty circuit due to the mal-operation of distance protection relays. Distance protection relay quantity swings further indicate that the isolation of one circuit due to a fault may result in a system voltage instability situation. 
4. PV, QV curves plotted for some selected busses further justify the occurrence of system voltage instability following one circuit outage of the $\mathrm{KB}$ line due to a fault.

\section{Remedial Measures}

1. Mechanisms which are incorporated in distance relays for blocking relay quantity swings were not modelled due to the lack of exact information. Hence it was assumed that relay quantity swing blocking features are not incorporated or inactivated.

There are several techniques used in the distance protection relays to avoid maloperations caused due to the relay quantity swings. Introduction of blinders to limit the operational region and usage of relays with elliptical characteristics instead of circular characteristics are commonly applied methods. However, those two methods restrict relay operating region and reduce the sensitivity. In numerical relays the impedance locus tracking techniques is widely used to overcome relay quantity swings. It is recommended to study thoroughly the effectiveness of the techniques used to block the relay quantity swings when transmission line distance protection schemes are implemented in the future.
2. The reactive power sources available at load centres are not adequate. More reactive power sources should be added around load centres. All generators should be operated with minimum reactive power supply in normal operations ensuring availability of a fast reactive power reserve for emergency situations. As shown in the long term stability analysis, reactive power supply should be increased at a faster rate and less than $1.5 \mathrm{~s}$ period. It is recommended to install fast acting reactive power sources such as synchronous condenser or Static VAr Compensator (SVC). The size and places for new reactive power sources should be selected after conducting the reactive power planning study.

3. At present the transmission network planning security criteria is limited only to (n-1) outage conditions, i.e. outage of any one element of the transmission system at a time [4]. The presently adopting network security criteria in transmission network planning should be reviewed to cover total or partial system failures caused by the credible double circuit outages. Especially the threat on system security caused by double circuit contingencies of lines which have two circuits running on the same towers should be well addressed.

4. The situation will be worse when additional $150 \mathrm{MW}$ generation of the upper Kothmale power plant is dispatched through the same line. Since outage of a one circuit results in higher loading on the remaining healthy circuit of the $K B$ line [4]. As a consequence the impact on the system becomes more severe in the future if precautionary measures are not implemented. 
Table 1: Load flow results for both circuits of the $\mathrm{KB}$ line in service

\begin{tabular}{|c|c|c|c|c|c|}
\hline \multirow[b]{2}{*}{ Parameter } & \multicolumn{2}{|c|}{ Day Peak Load } & \multirow{2}{*}{$\begin{array}{l}\text { Night peak load } \\
\text { Hydro/thermal } \\
\end{array}$} & \multicolumn{2}{|c|}{ off peak Load } \\
\hline & Hydro & thermal & & Hydro & thermal \\
\hline Power demand/MW & 1300 & 1300 & 1800 & 800 & 800 \\
\hline $\begin{array}{ll}\begin{array}{l}\text { Reactive } \\
\text { demand/MVar }\end{array} & \text { power } \\
\end{array}$ & 718.5 & 718.5 & 766.8 & 200.5 & 200.5 \\
\hline Power generation/MW & 1323.9 & 1311.5 & 1838.7 & 816.6 & 811 \\
\hline 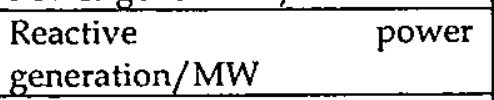 & 339.2 & 275.1 & 514.2 & -31 & -46 \\
\hline Power loss/MW & 23.9 & 11.5 & 38.7 & 16 & 11 \\
\hline Reactive power Loss (MVAr) & 207.2 & 149.5 & 325 & 85.4 & 71.5 \\
\hline Reactive shunts/MVAr & -294.9 & -294.9 & -288.9 & 0 & 0 \\
\hline $\begin{array}{l}\text { Line Generated reactive } \\
\text { power/MVAr }\end{array}$ & 291.6 & 298.1 & 288.7 & 316.5 & 314.5 \\
\hline $\begin{array}{l}\text { Power flow on the } \mathrm{KB} \\
\text { line/MW }\end{array}$ & 149.4 & 55.3 & 201.9 & 131.4 & 82.1 \\
\hline $\begin{array}{l}\text { Reactive power flow on the } \\
\text { KB line/MVAr }\end{array}$ & 71 & 48.3 & 86.6 & 19.1 & 6.1 \\
\hline Biyagama $220 \mathrm{kV}$ voltage/pu & 0.969 & 0.985 & 0.953 & 1.027 & 1.037 \\
\hline Kotugoda $220 \mathrm{kV}$ voltage/pu & 0.943 & 0.977 & 0.939 & 1,025 & 1.035 \\
\hline Kelanitissa $220 \mathrm{kV}$ voltage/pu & 0.969 & 0.968 & 0.955 & 1.027 & 1.041 \\
\hline Pannipitiya $220 \mathrm{kV}$ voltage/pu & 0.972 & 0.985 & 0.954 & 1.025 & 1.012 \\
\hline
\end{tabular}

Table.2: Load flow results for one circuit of the $\mathrm{KB}$ line in service

\begin{tabular}{|l|l|l|l|l|l|}
\cline { 2 - 7 } \multicolumn{1}{c|}{} & \multicolumn{2}{c|}{ Day Peak Load } & \multicolumn{2}{l|}{$\begin{array}{l}\text { Night peak } \\
\text { load }\end{array}$} & \multicolumn{2}{l|}{ off peak Load } \\
\hline Parameter & Hydro & thermal & $\begin{array}{l}\text { Hydro/ } \\
\text { thermal }\end{array}$ & Hydro & thermal \\
\hline Power demand/MW & 1300 & 1300 & 1800 & 800 & 800 \\
\hline Reactive power demand/MVar & 718.5 & 718.5 & 766.8 & 200.5 & 200.5 \\
\hline Power generation/MW & 1329.8 & 1311.8 & 1847.2 & 819.2 & 812.1 \\
\hline Reactive power generation/MW & 388.1 & 287.1 & 571.2 & 5.7 & -22.5 \\
\hline Power loss/MW & 29.8 & 11.8 & 47.2 & 19.2 & 12.1 \\
\hline Reactive power Loss (MVAr) & 239.8 & 151.3 & 369.8 & 101.3 & 77.2 \\
\hline Reactive shunts/MVAr & -298.7 & -298.5 & -294.6 & 0 & 0 \\
\hline $\begin{array}{l}\text { Line Generated } \\
\text { power/MVAr }\end{array}$ & 271.1 & 284.2 & 270.8 & 293.5 & 295.6 \\
\hline Power flow on the KB line/MW & 270.2 & 100.3 & 342.2 & 237.4 & 148.2 \\
\hline $\begin{array}{l}\text { Reactive power flow on the KB } \\
\text { line/MVAR }\end{array}$ & 147.2 & 66.8 & 180.2 & 60.9 & 24.4 \\
\hline Biyagama 220kV voltage/pu & 0.93 & 0.979 & 0.917 & 1.004 & 1.025 \\
\hline Kotugoda 220kV voltage/pu & 0.915 & 0.971 & 0.894 & 1.003 & 1.025 \\
\hline Kelanitissa 220kV voltage/pu & 0.931 & 0.962 & 0.92 & 1.005 & 1.03 \\
\hline Pannipitiya 220kV voltage/pu & 0.948 & 0.98 & 0.919 & 1.002 & 1.021 \\
\hline
\end{tabular}




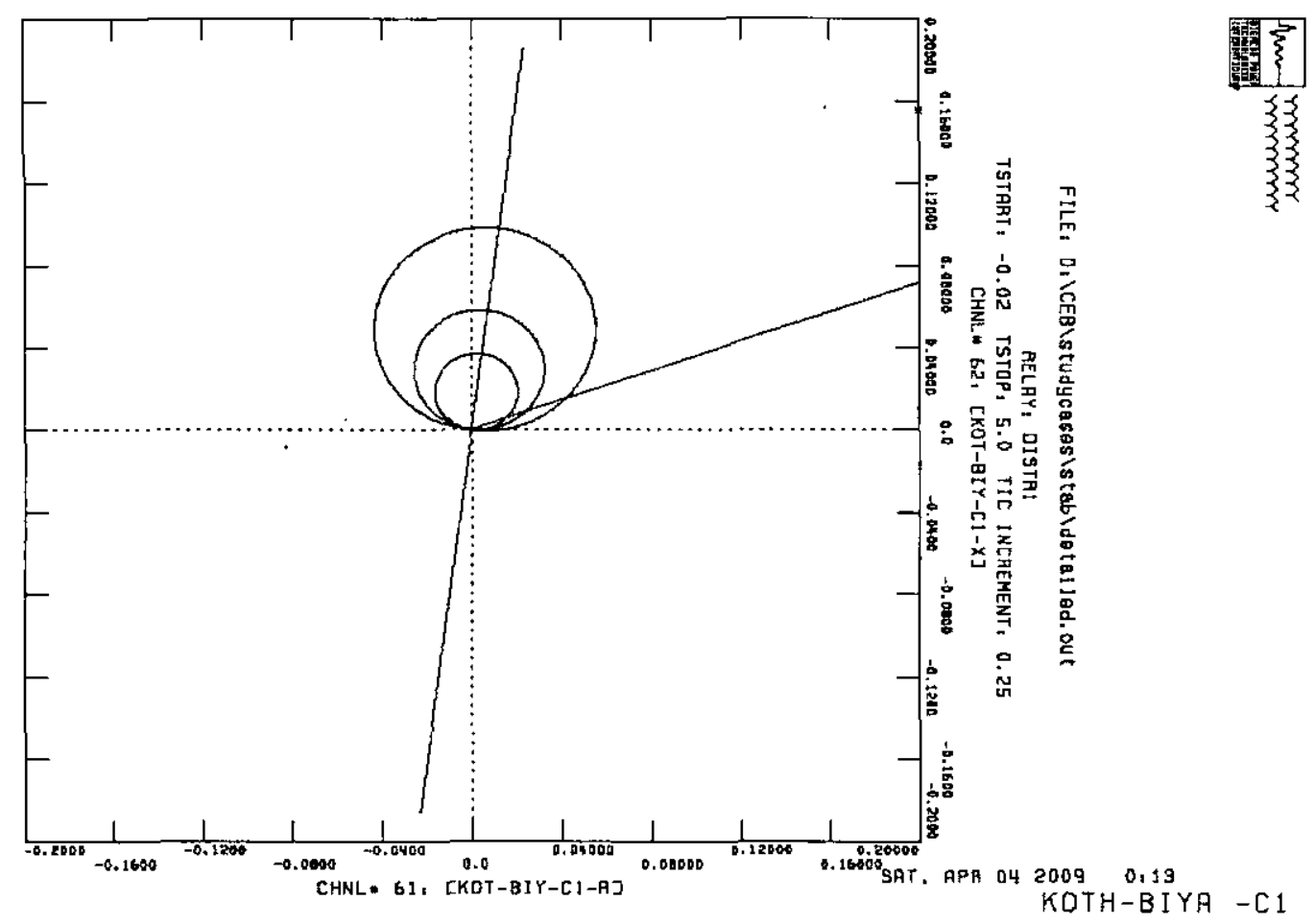

Fig.1: Apparent resistance vs. reactance seen by Mho relay for circuit No.1 of the KB line at Kathmale end superimposed on relay characteristics

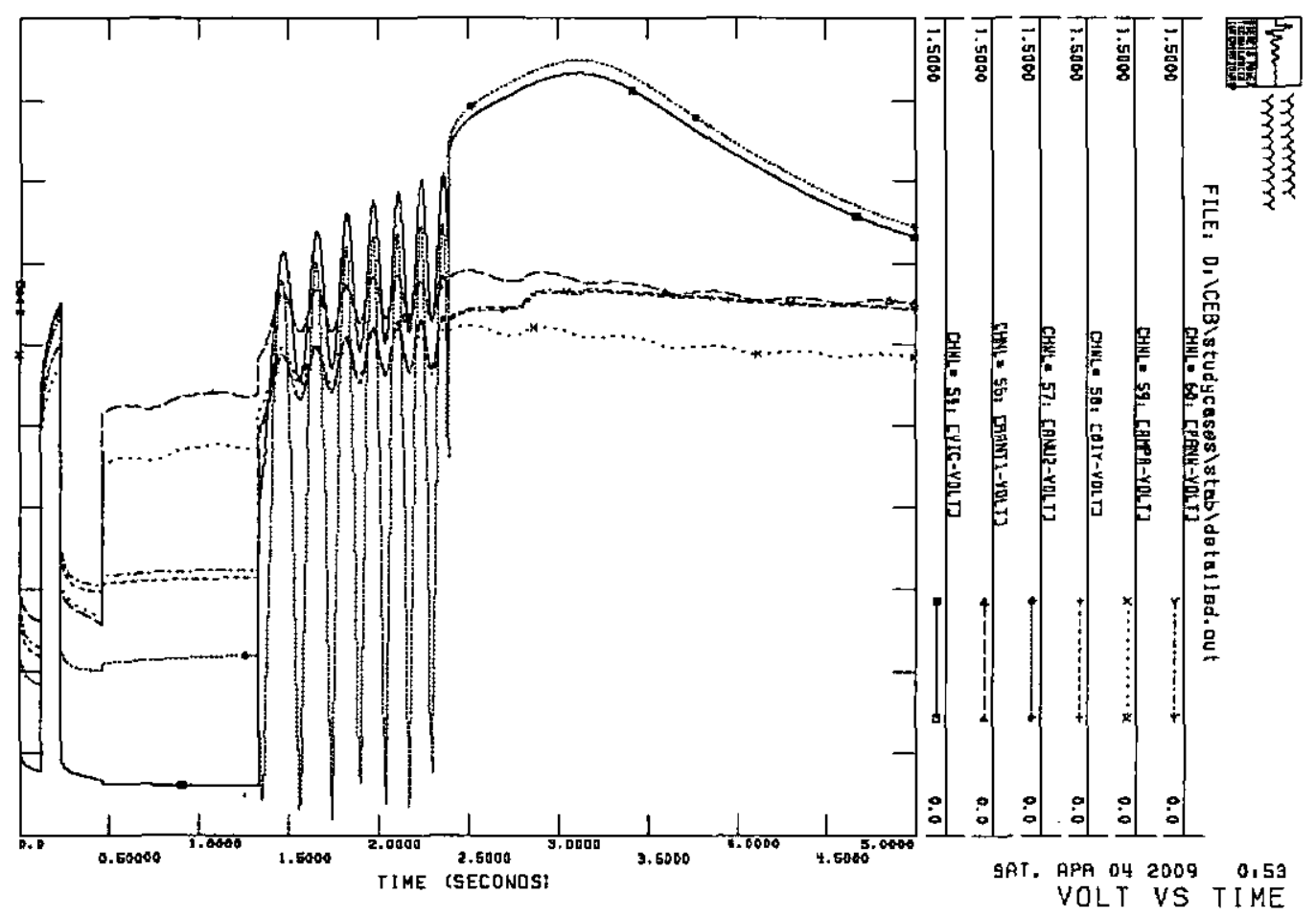

Fig.2: Bus bar voltage vs time for Victoria, Biyagama, Pannipitiya $220 \mathrm{kV}$ busses and Ampara $132 \mathrm{kV}$ bus. 


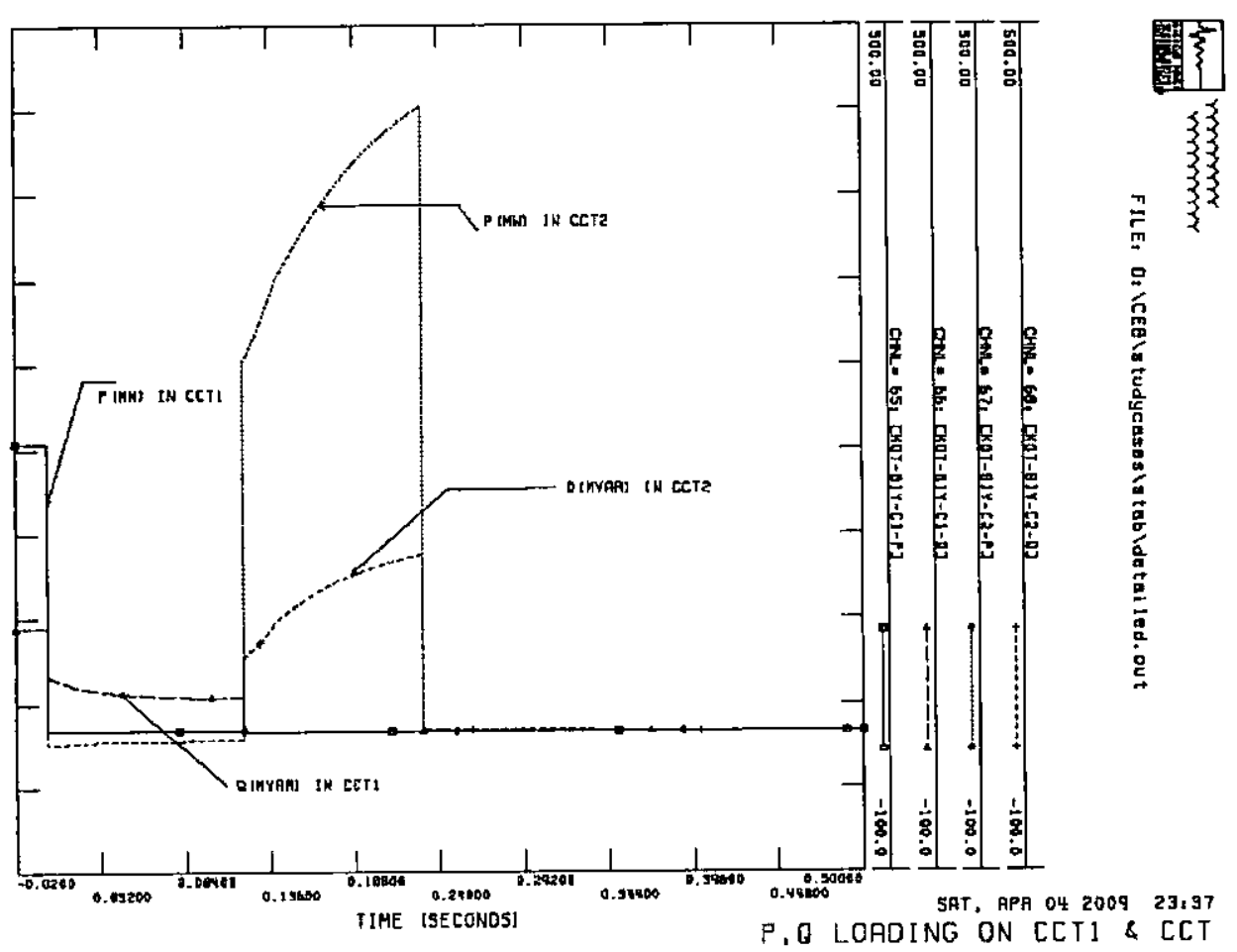

Fig.3: Active and reactive power flow of circuit 1and 2 of the KB line

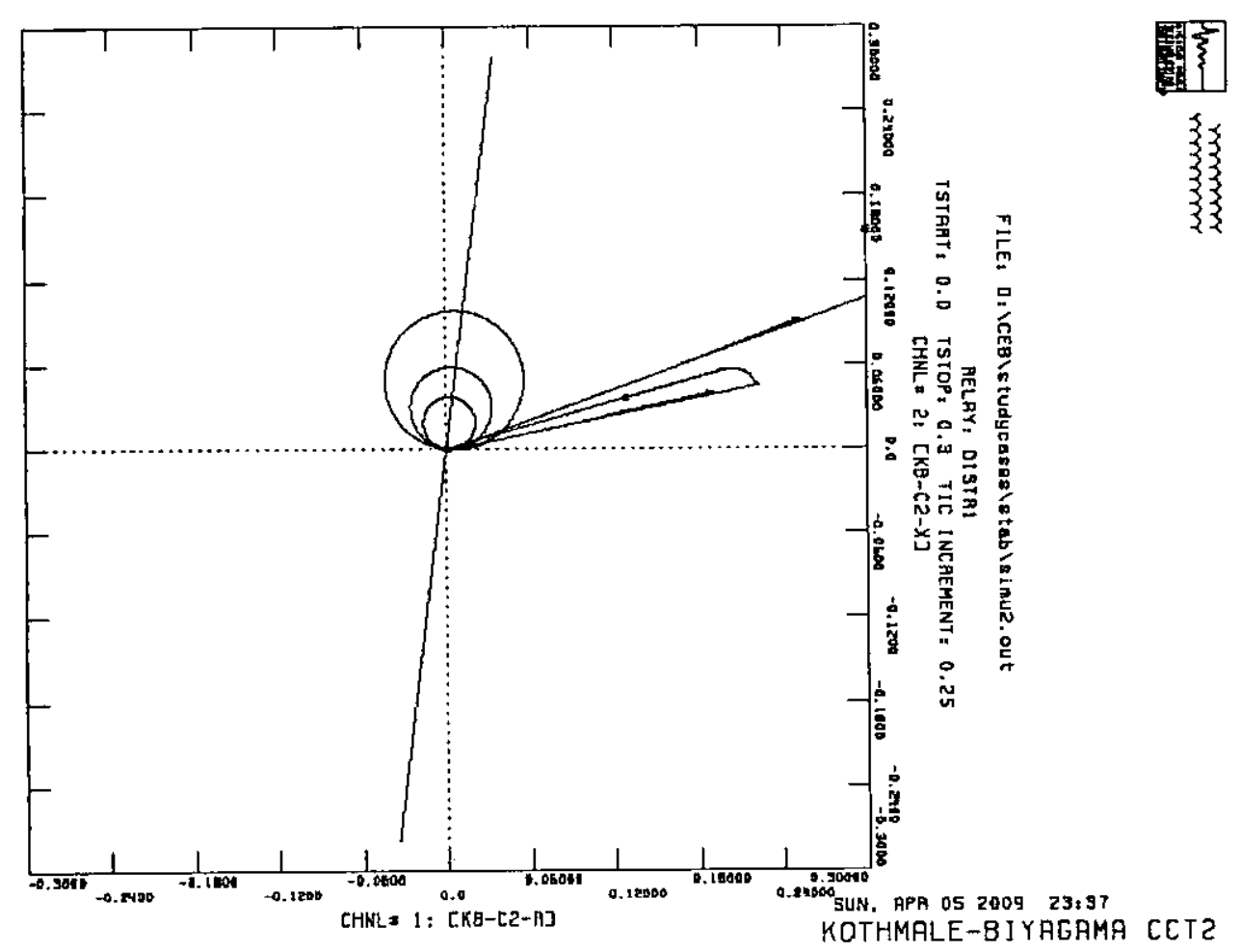

Fig.4: Apparent resistance vs reactance seen by Mho relay for circuit No.2 of the KB line at Kothmale end superimposed on relay characteristics. 


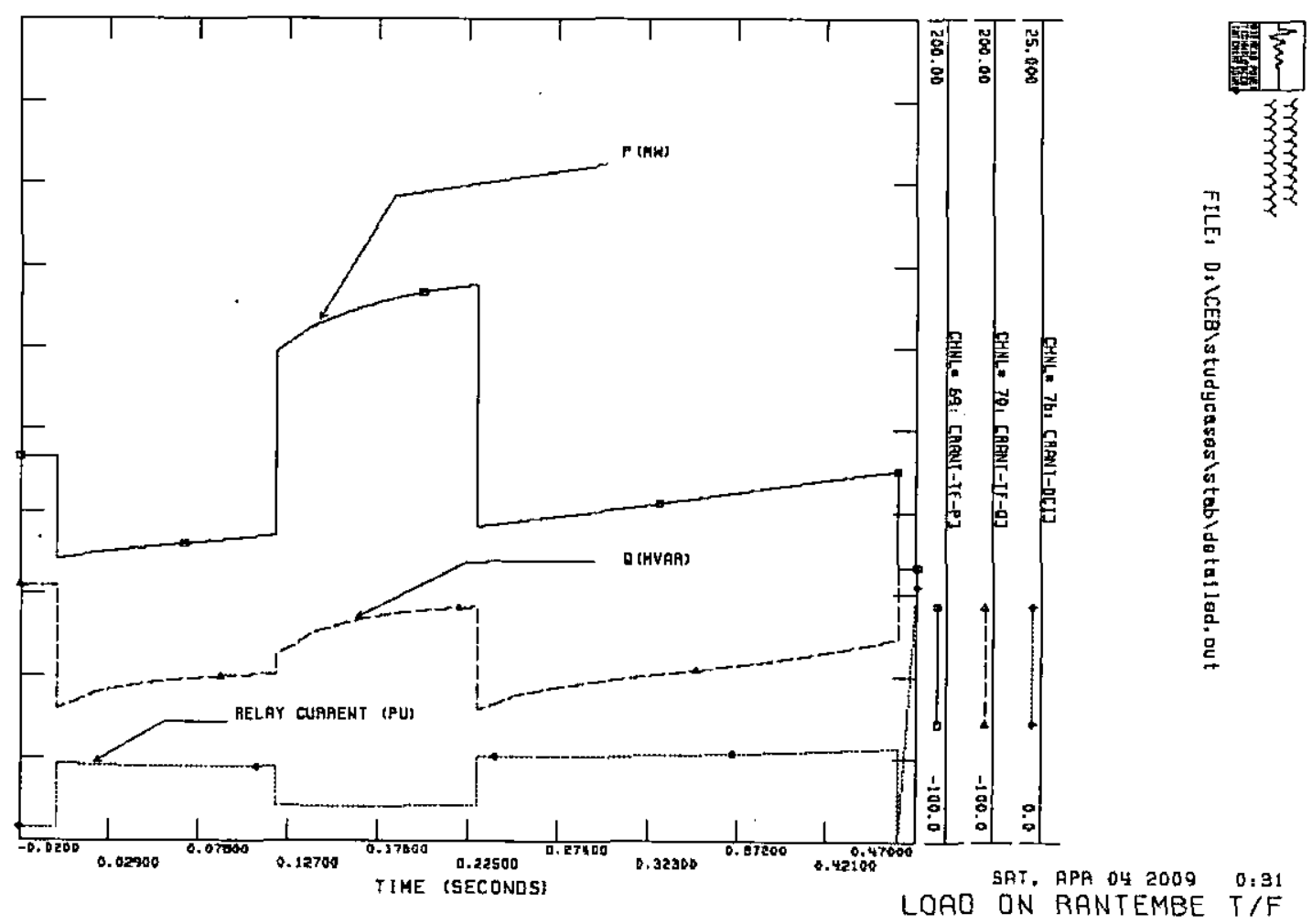

Fig.5: Active, Reactive power variation through Rantembe 220/132kV transformer and current flow detected by over current relay.

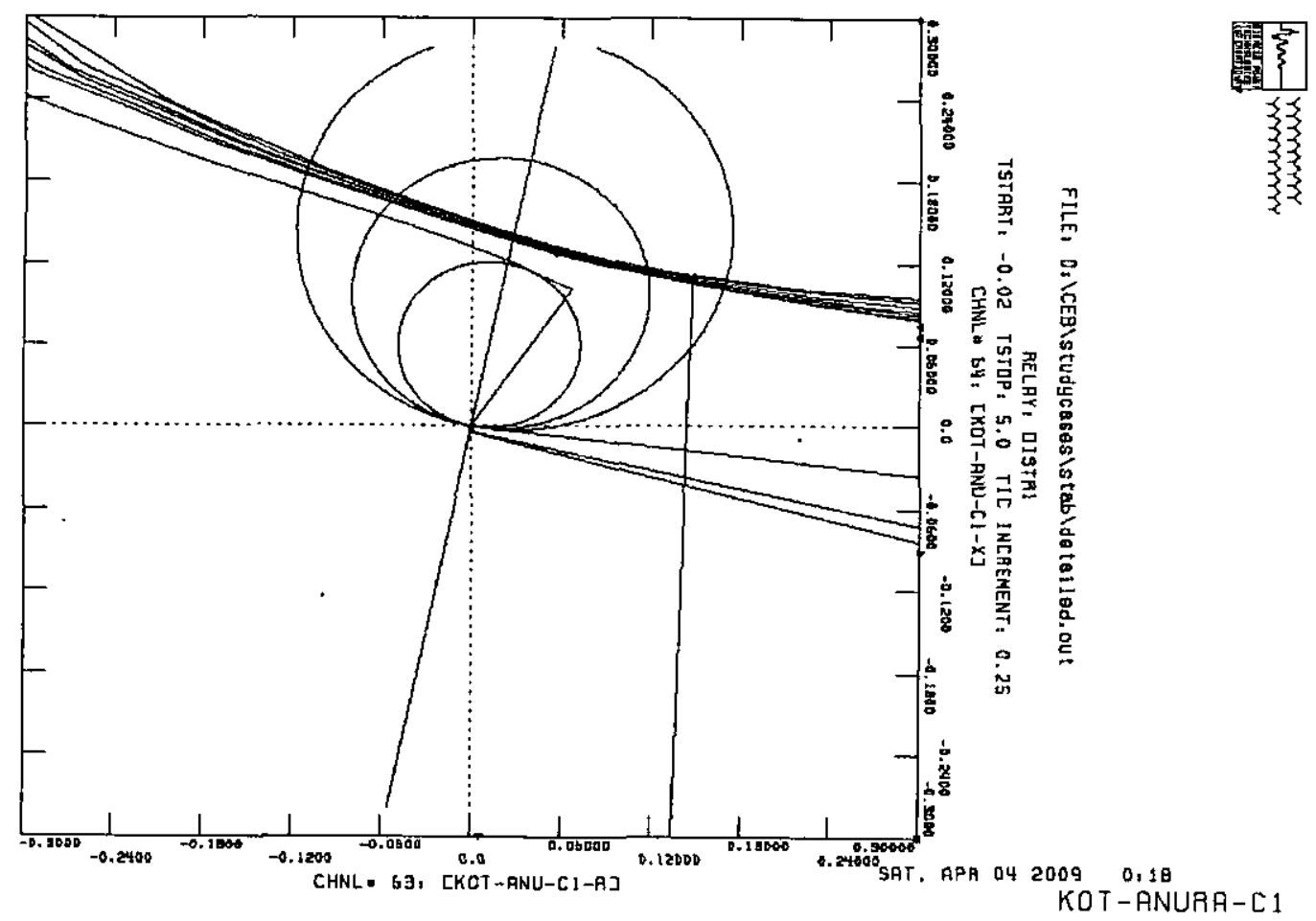

Fig.6: Apparent resistance vs reactance seen by Mho relay for Kothmale-Anuradhapura 220kV line at Kothmale end superimposed on relay characteristics 


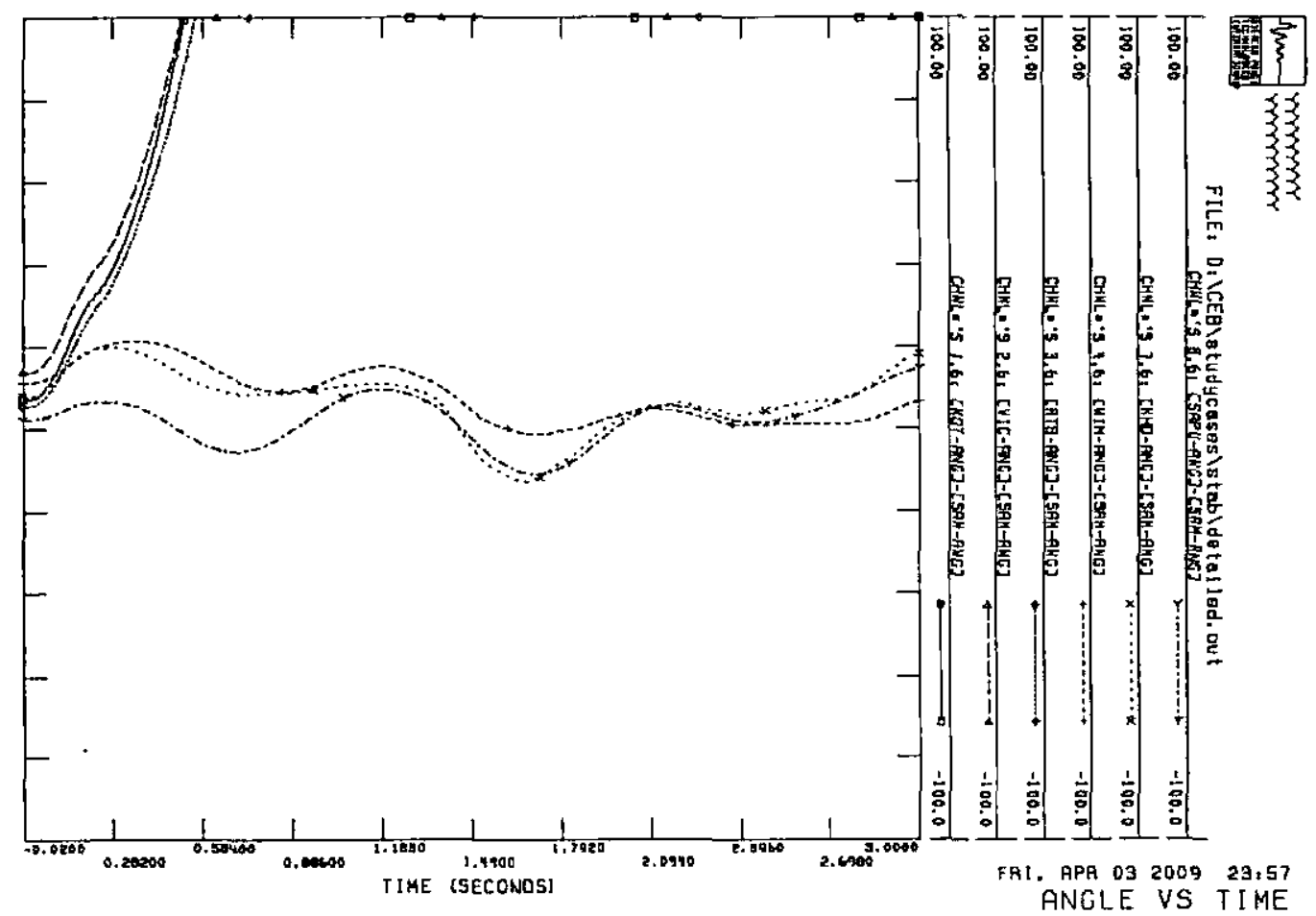

Fig.7: Relative angle variation Vs time curves for selected generators

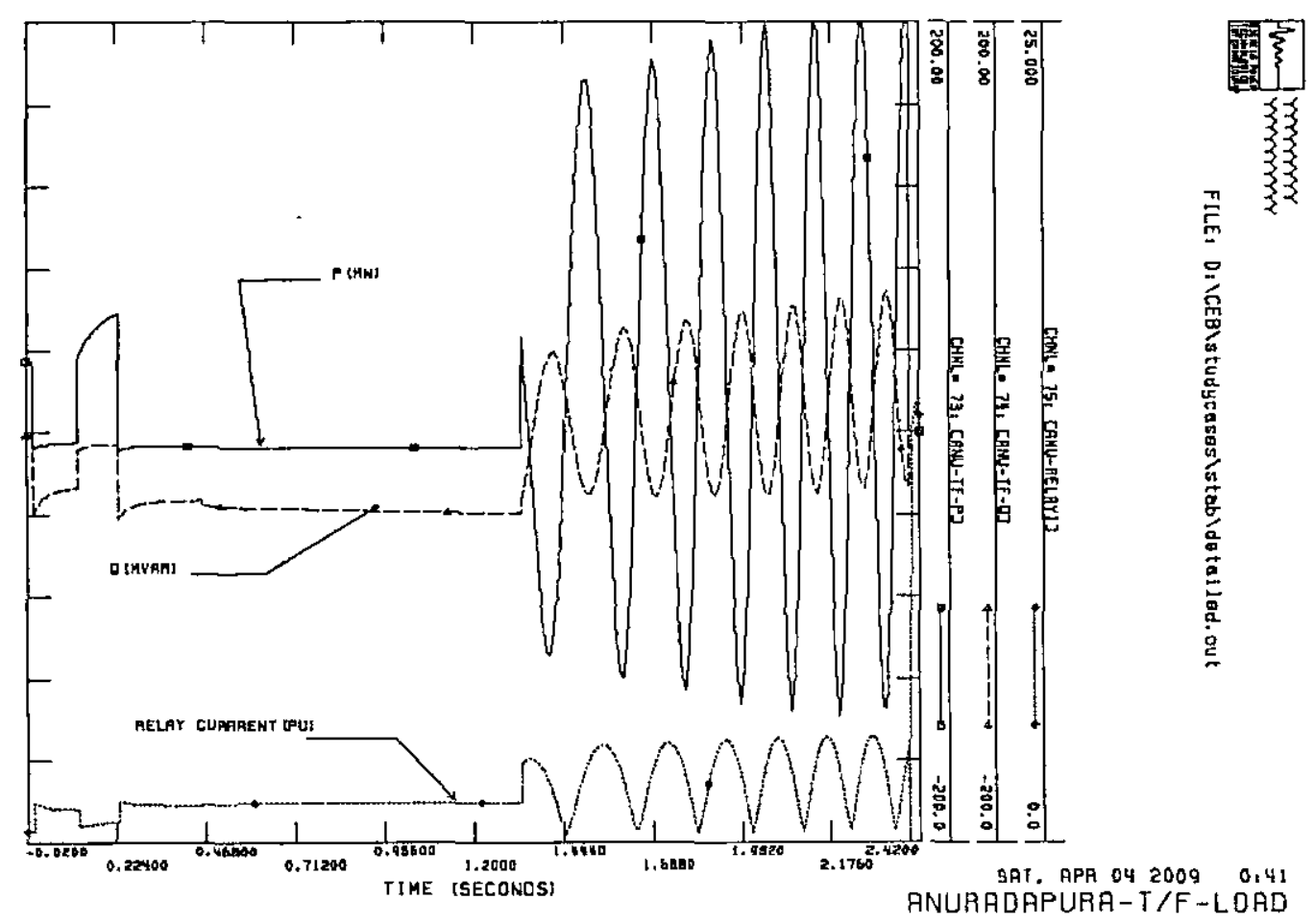

Fig.8: Active, Reactive power variation through Anuradhapura 220/132kV transformer and current flow detected by over current relay. 


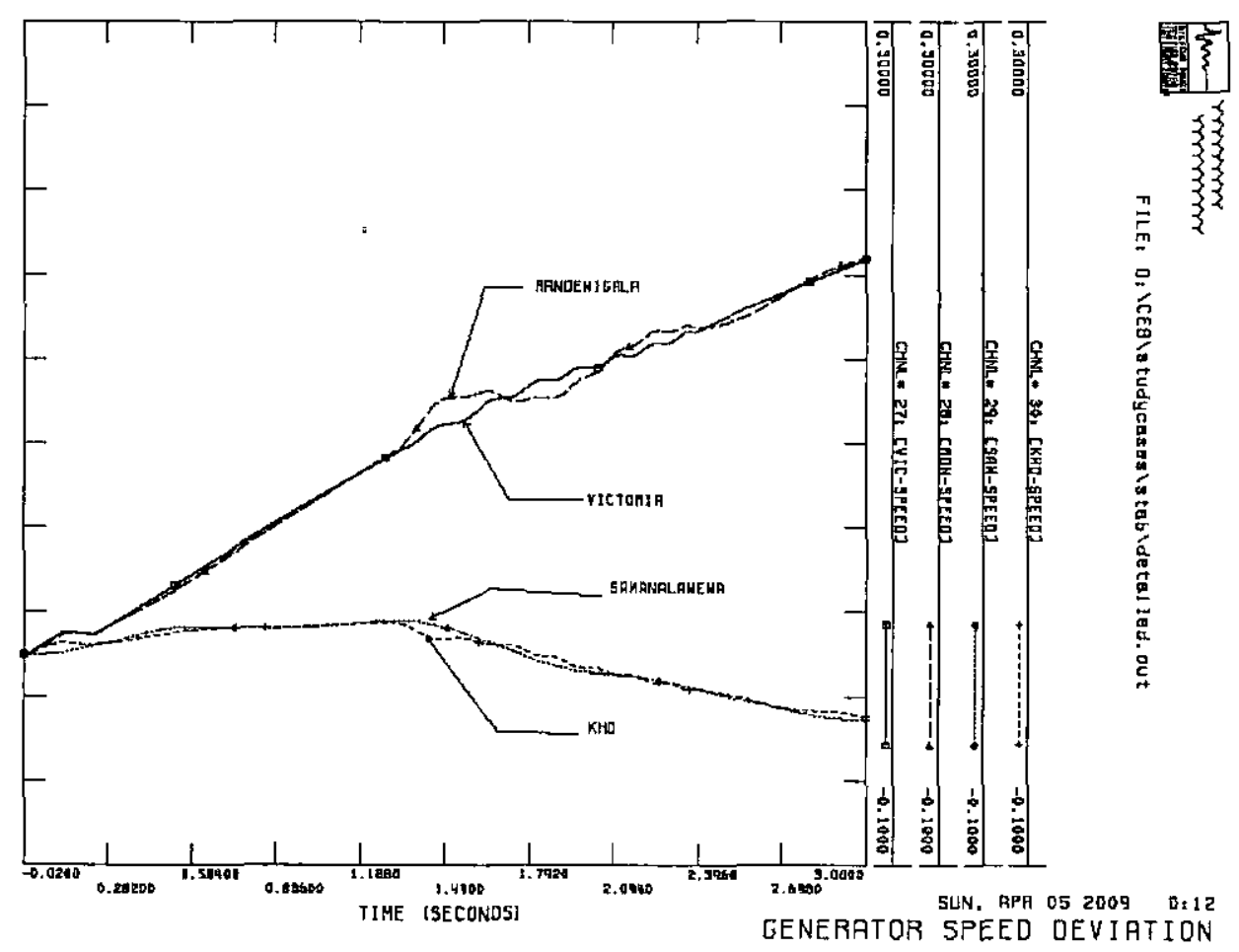

Fig.9: Speed variation of selected generators

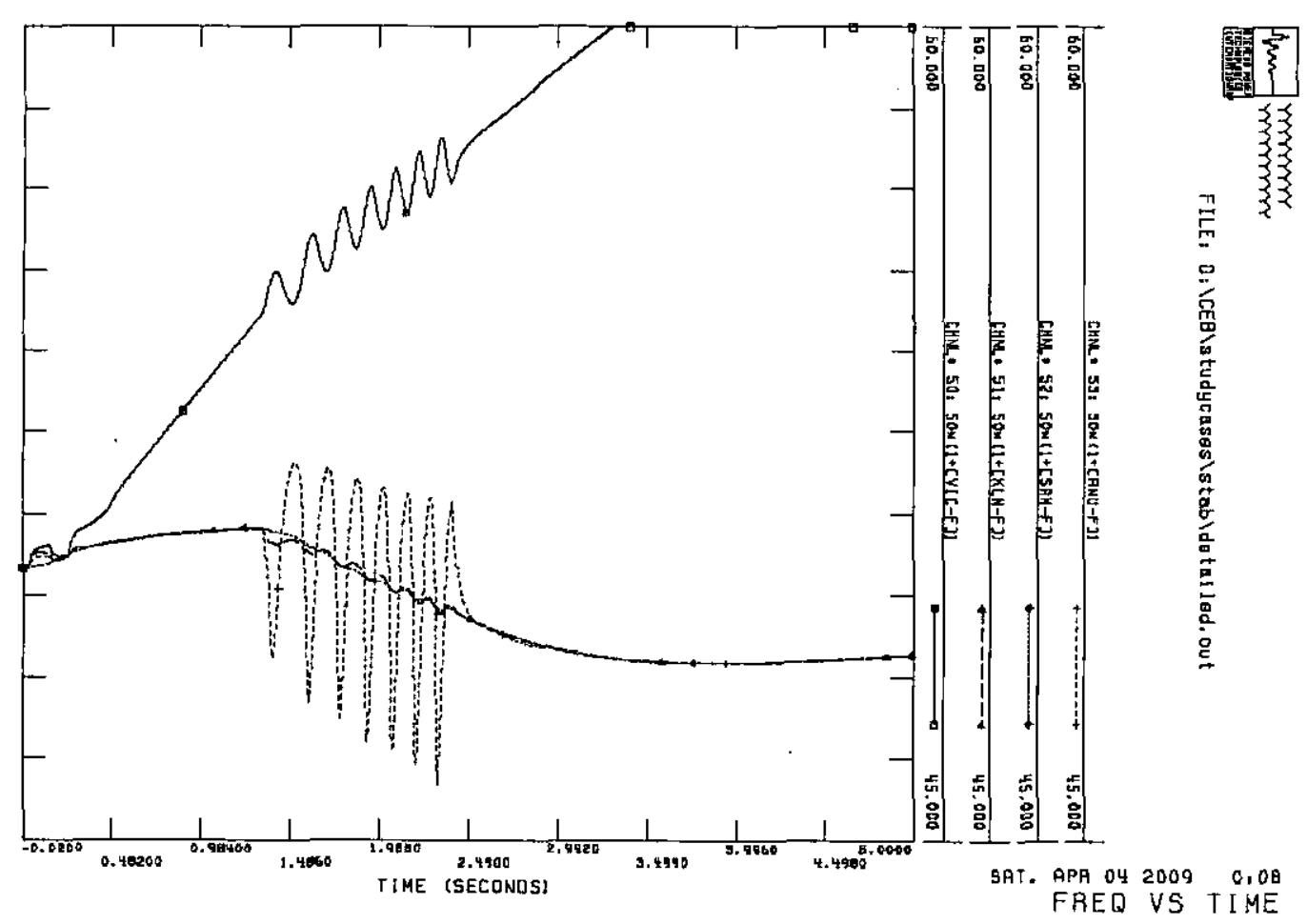

Fig.10: Frequency Vs time variation (solid curve for Maxwell Complex buses and other curves for some sleeted busses on rest of the system) 


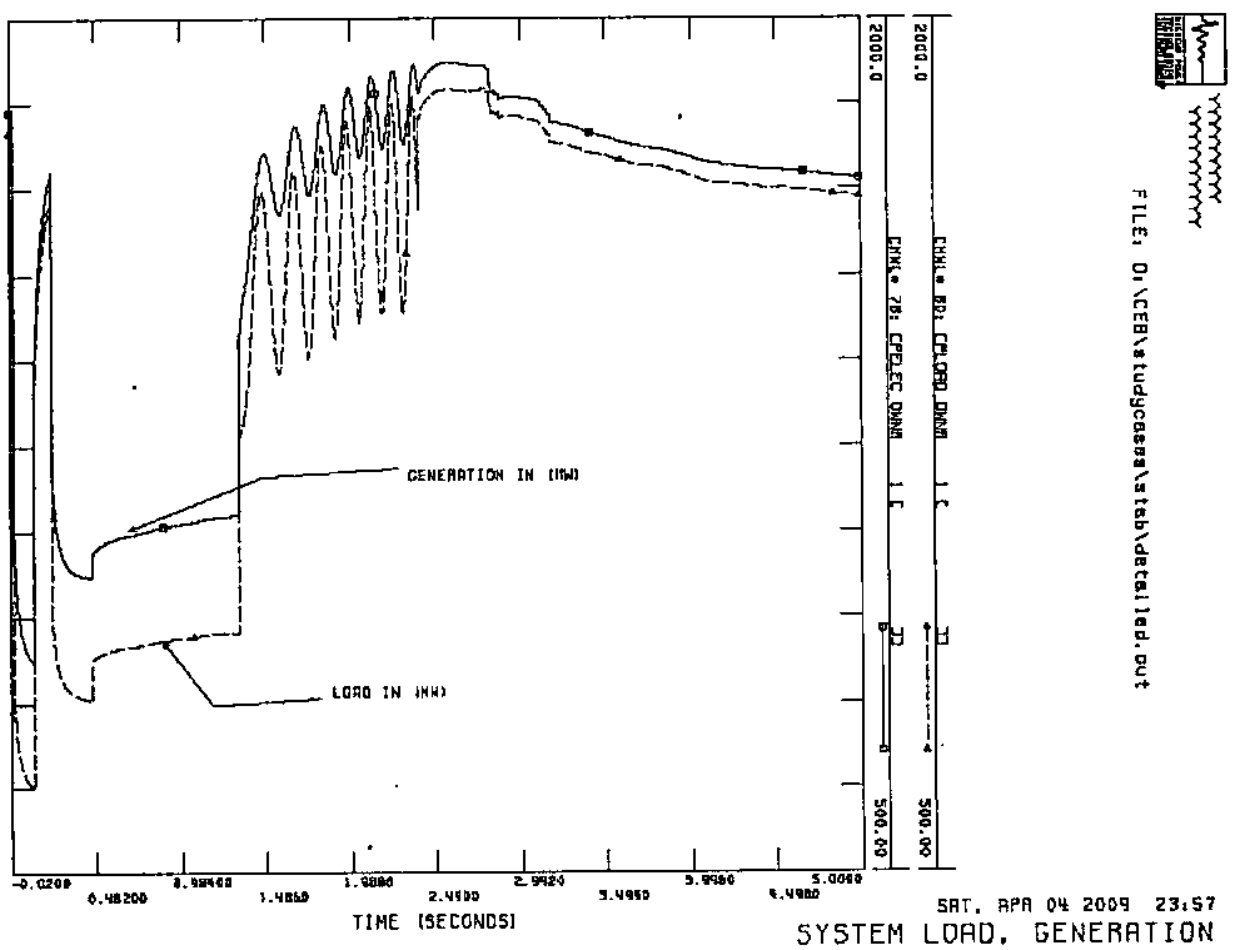

Fig.11: Time variation of active power demand and generation of the total system

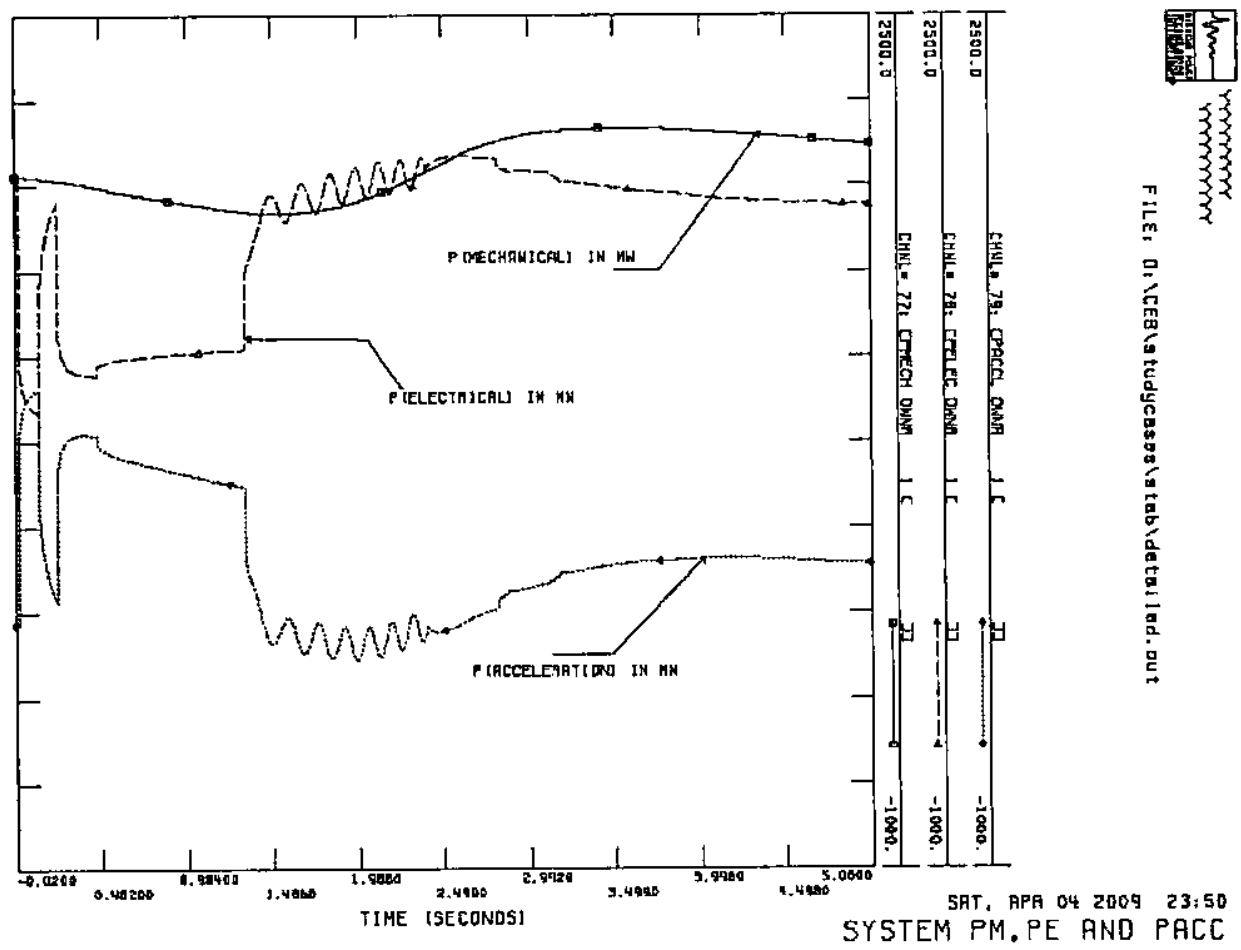

Fig.12: Time variation of electrical, mechanical and accelerated power of the system 


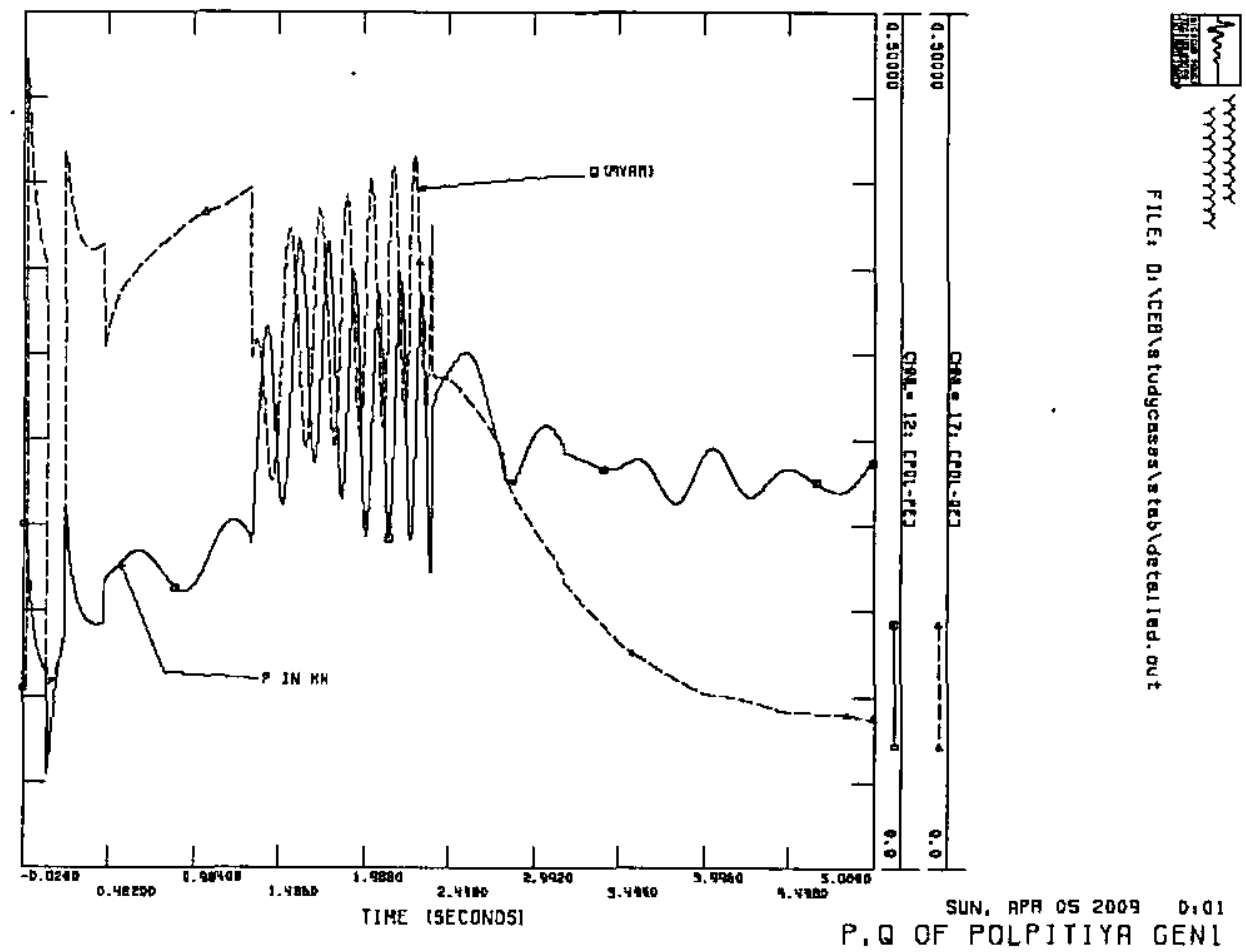

Fig.13: Time variation of active and reactive power (in pu) of Polpitiya generator

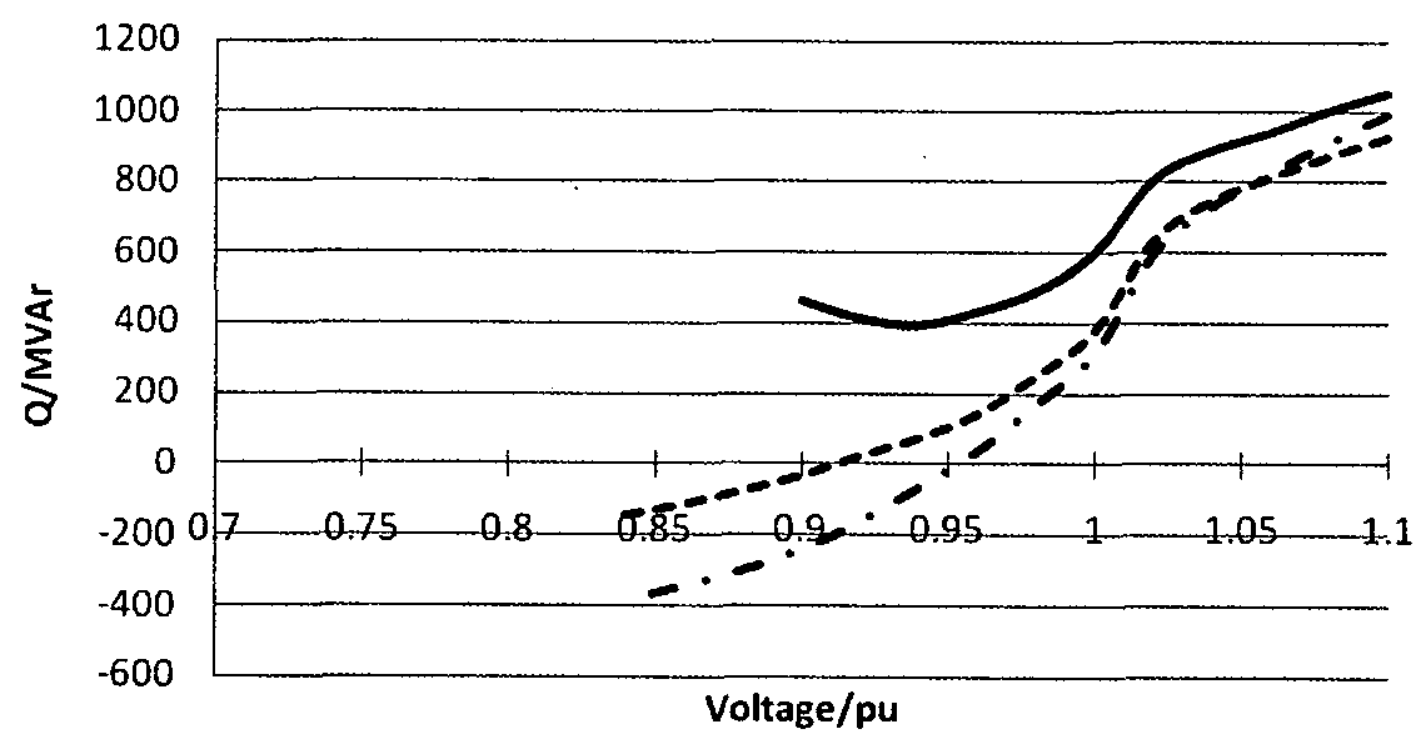

- - Two circuit on $\quad---$ One circuit off $\longrightarrow$ Two circuit off

Fig.14: QV characteristic of Biyagama $220 \mathrm{kV}$ bus at different outage conditions 


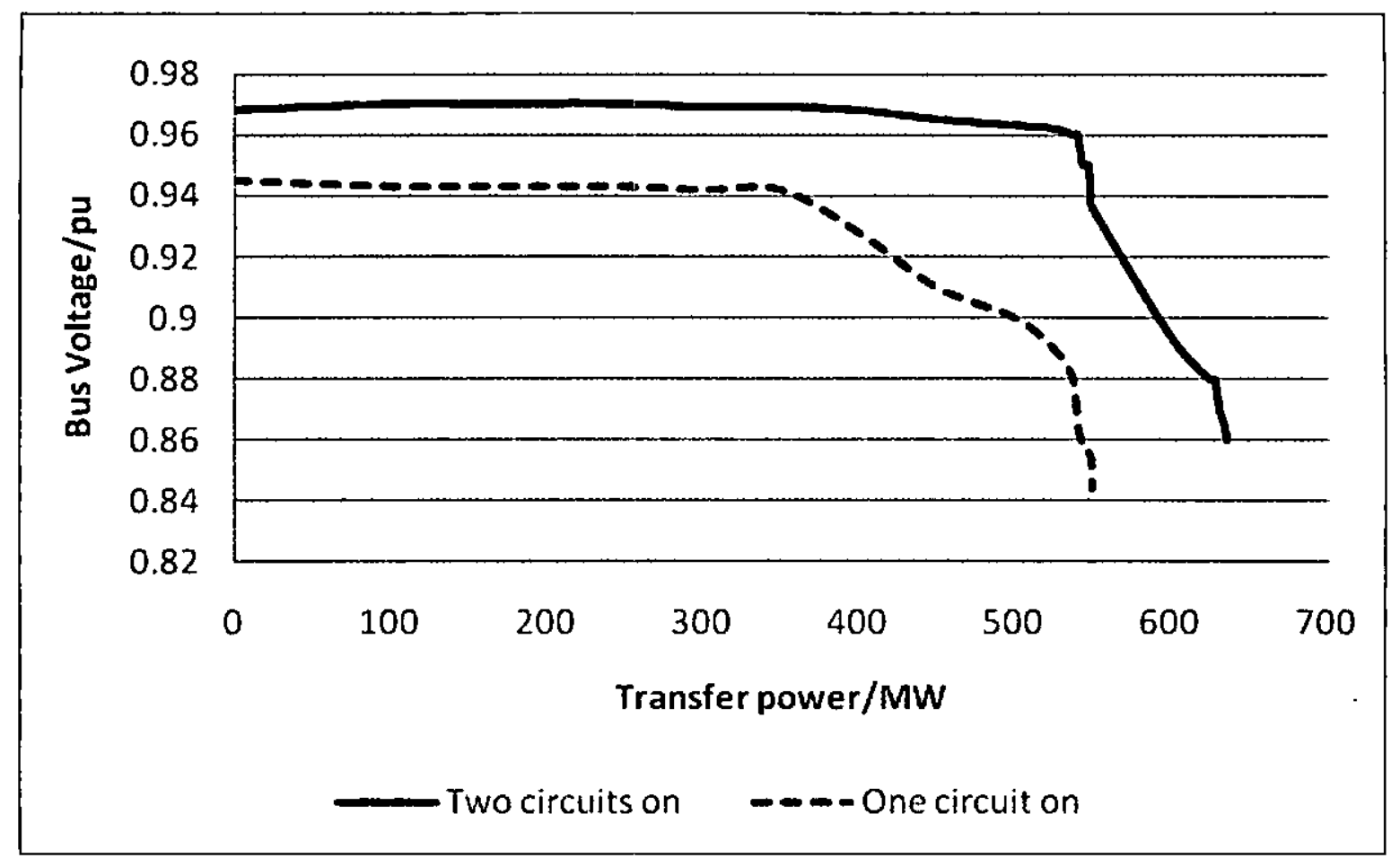

Fig.15: P, V characteristic of Biyagama $220 \mathrm{kV}$ bus at different outage conditions

Table 3: Results of $P, Q$ curve analysis

\begin{tabular}{|c|c|c|c|c|c|}
\hline Bus name & $\begin{array}{l}\text { Voltage } \\
/ \mathrm{kV}\end{array}$ & $\begin{array}{l}\text { Critical } \\
\text { voltage/pu }\end{array}$ & $\begin{array}{l}\text { Voltage } \\
\text { margin/pu }\end{array}$ & $\begin{array}{l}\text { Reactive } \\
\text { margin/pu }\end{array}$ & $\begin{array}{l}\text { Reactive power } \\
\text { injection to bring } \\
\text { voltage to } 0.95 \mathrm{pu}\end{array}$ \\
\hline \multicolumn{6}{|c|}{ Two circuits in service } \\
\hline Biyagama & 220 & 0.84 & 0.11 & 400 & 0.0 \\
\hline Pannipitiya & 220 & 0.76 & 0.18 & 325 & 65.0 \\
\hline Kelanitiss & 132 & 0.7 & 0.26 & 403 & -68.5 \\
\hline Sapugaskanda & 132 & 0.68 & 0.28 & 394 & -62.0 \\
\hline \multicolumn{6}{|c|}{ One circuit outage } \\
\hline Biyagama & 220 & 0.85 & 0.05 & 150 & -32.0 \\
\hline Pannipitiya & 220 & 0.78 & 0.1 & 67 & 75.0 \\
\hline Kelanitiss & 132 & 0.72 & 0.24 & 163 & -73.0 \\
\hline Sapugaskanda & 132 & 0.7 & 0.26 & 140 & -54.0 \\
\hline
\end{tabular}


Table 4: Results of $P, V$ curve analysis

\begin{tabular}{|c|c|c|c|c|}
\hline Bus name & $\begin{array}{l}\text { Voltage } \\
/ \mathrm{kV}\end{array}$ & $\begin{array}{l}\text { Nose point } \\
\text { voltage/pu }\end{array}$ & $\begin{array}{l}\text { Nose point } \\
\text { Load/MW }\end{array}$ & $\begin{array}{l}\text { Maximum Possible power } \\
\text { transfer/MW }\end{array}$ \\
\hline \multicolumn{5}{|c|}{ One circuits in service } \\
\hline Biyagama & 220 & 0.963 & 500 & 450 \\
\hline Pannipitiya & 220 & 0.969 & 400 & 450 \\
\hline Kelanitiss & 132 & 0.987 & 350 & 350 \\
\hline Sapugaskanda & 132 & 0.993 & 300 & 400 \\
\hline \multicolumn{5}{|c|}{ Two circuits in service } \\
\hline Biyagama & 220 & 0.944 & 300 & 300 \\
\hline Pannipitiya & 220 & 0.935 & 350 & 400 \\
\hline Kelanitiss & 132 & 0.971 & 350 & 300 \\
\hline Sapugaskanda & 132 & 0.976 & 250 & 250 \\
\hline
\end{tabular}

\section{References:}

1. System Control Centre, Ceylon Electricity Board, Annual report on System Operations

2. Nippon Koei Co. Ltd, Master Plan for Development of the Transmission System of the Ceylon Electricity Board, January 1997.
3. Leonard L Grigsby, Power system stability and control, CRC Press, 2007

4. Long Term Transmission development Plan 2005-2014, Ceylon Electricity Board, December 2005. 